\title{
重庆合川地区中二叠世晚期腕足动物群落物种 多样性与生态系统功能(生产力)的关系
}

曾勇 ${ }^{(1)}$ (2) $^{*}$ 姜立君 ${ }^{(1)}$, 柯妍 ${ }^{(1)}$, 吕倩 ${ }^{(1)}$, 赵莉 ${ }^{(1)}$, 梁家栋 ${ }^{(1)}$, 胡涵 ${ }^{(1)}$, 令狐博 ${ }^{(1)}$

(1) 中国矿业大学资源与地球科学学院, 徐州 221116;

(2) 现代古生物学和地层学国家重点实验室, 中国科学院南京地质古生物研究所, 南京 210008

*E-mail: zyzy@cumt.edu.cn

收稿日期: 2011-12-22; 接受日期: 2012-04-23

现代古生物学和地层学国家重点实验室(中国科学院南京地质古生物研究所)课题项目(编号：123115)和中央高校基本科研业务费专项资 金(编号: 2010LKDZ01)资助

\begin{abstract}
摘要以重庆市合川地区中二叠世晚期腕足动物群落物种多样性的演变为研究对象, 从地 史发展的角度探讨了物种多样性与群落生产力的关系. 研究表明, 物种多样性是由多种指标来 体现的, 它与生产力的关系是个十分复杂的问题, 很难用一种假说去表述. 物种多样性与群落 生产力的关系受到环境及群落演化的制约，当群落演替正常进行时，物种丰富度指数、物种多 样性指数、均匀度指数与生产力的关系符合目前 4 种假说中的第 3 种假说, 即, 彼此呈线性相 关关系. 但当环境干扰超过群落承受能力时, 不仅群落演替终止而被另一群落取代, 而且物种 丰富度指数、物种多样性指数、均匀度指数与生产力的关系在环境的千扰下发生了逆变, 彼此 出现负相关关系. 只有生态优势度与生产力的关系基本符合第 3 种假说，彼此呈线性相关关系. 可见, 生产力与多样性之间呈线性关系的假说应建立在群落演替正常进程中这一前提下.
\end{abstract}

关键词

重庆合川

中二叠世晚期

腕足动物群落

物种多样性

生产力
18 世纪以来，人类活动对自然环境造成破坏的 同时, 也给生物多样性带来了巨大危害. 据研究, 全 球物种的灭绝速度是人类出现以前的 100 1000 倍 ${ }^{[1,2]}$. 生物多样性的丧失, 其潜在的生态后果如何? 是否 会损害生态系统的功能? 不仅在生态学研究中具有 重大的理论价值, 而且对于人类保护环境、维持生态 系统过程的良性发展都有着决定性的指导意义. 生 物多样性和生态系统功能关系的研究, 成为生态学 和环境学的一个中心议题, 并在生态学家中引发了 一场激烈的争论 ${ }^{[3 \sim 7]}$. 生物多样性与生态系统功能关 系的争论归纳起来, 实质就是多样性与生产力的关 系、多样性与稳定性的关系、多样性与生态系统可持
续性的关系等三个方面的争论. 本文以地史时期的 古海洋动物群落为研究对象, 通过对重庆市合川地 区中二叠世晚期腕足动物群落物种多样性的演变来 探讨物种多样性与群落生产力的关系. 从而为生物 多样性与生态系统功能关系的研究, 提供来自古生 物地层学方面的科学规律和佐证.

\section{1 地质背景材料和研究方法}

\section{1 实测地层剖面介绍}

剖面位于重庆市合川县三汇坝镇通往华菳山煤 矿公路旁的大水沟内, 地层出露完好 ${ }^{[4]}$. 茅口组总厚

英文引用格式: Zeng Y, Jiang L J, Ke Y, et al. The relationship between species diversity and ecosystem function (productivity) of the late Middle Permian brachiopods community at the region of Hechuan, Chongqing, China. Science China: Earth Sciences, 2012, 55: 1248-1254, doi: 10.1007/s11430-012-4437-9 
度 $216.5 \mathrm{~m}$, 共划分为 12 层. 根据岩性组合特征可分 为两段: 下部称为五十三梯段、上部称为倒钻岩段. 五十三梯段由第 1 层至第 6 层组成, 厚 $72.6 \mathrm{~m}$. 主 要由灰黑色厚层状石灰岩组成, 并夹有多层钻质泥 岩、页岩及泥灰岩. 倒钻岩段由第 7 层至第 12 层组 成, 厚 $143.9 \mathrm{~m}$. 主要由灰白色、灰色、灰黑色薄层至 厚层状石灰岩组成, 底部夹薄层泥质灰岩, 未见钻质 泥岩、页岩等碎屑岩层.

\section{2 腕足动物的地层分布}

在前期研究的基础上 ${ }^{[8]}$, 本次对茅口组各层的腕 足动物化石进行了重新审查, 共鉴定出 18 属 26 种, 分别属于 3 目 8 超科 13 科, 其地层分布及个体数量 情况见图 1 所示.

\section{3 研究方法}

物种多样性与生态系统功能关系的研究中, 生 产力被认为是受生物多样性影响的一个重要的生态 系统功能特征 ${ }^{[3]}$, 表明生产力水平的高低是生态系统 功能的重要表现之一.

目前, 关于生产力和多样性之间的关系存在 4 种 主要观点 ${ }^{[9]}$ : 一是“沉余种”假说. 该假说认为, 生态 系统中损失的一些冗余物种不会降低他们生产物质 的能力, 因此物种多样性与生产力不呈相关关系; 二 是认为简单系统的生产力高于生物多样性高的复杂 系统; 三是认为生产力与多样性之间的关系是线性 关系, 即在生产力增加时多样性也在增加; 四是认为 生产力和多样性呈钟型的曲线关系, 即多样性在低 水平时随生产力增加而增加, 在生产力为中等水平 时其多样性最大, 但最终在达到足够高的生产力时 反而下降 ${ }^{[10 \sim 13]}$.

\subsection{1 物种多样性}

物种多样性是一个区域或一个生态系统可测定 的生物学特征, 是生物多样性在物种水平上的表现形 式, 因此一般用物种多样性指标来分析生物多样性. 目前常采用的物种多样性测度指数有物种丰富度指 数、物种多样性指数、均匀度指数以及生态优势度 ${ }^{[14]}$.

(1) 物种丰富度指标以 Margalef 指数 (d) 为代表, 它是测定一定空间范围内的物种数目以表达生物的 丰富程度: $d=(S-1) / \ln N$.

(2) 物种多样性指数是将物种丰富度与种的多
度结合起来的函数. 以 Shannon-wiener 指数 $(H)$ 为代 表: $H=-\Sigma P i \times \ln P i$.

(3) 物种均匀度指数 $(E): E=H / \ln S$.

(4) 生态优势度 $(D): D=\Sigma P i^{2}$.

上面各式中, $N$ 为个体总数; $S$ 为生态系统中物 种数目, $P i$ 为第 $i$ 个物种的个体数与群落总个体数之 比. 生态优势度、均匀度和物种多样性指数有密切关 系. 物种多样性指数与物种均匀度呈正相关, 而与生 态优势度呈负相关. 多样性指数越高, 生态优势度越 小, 多样性指数越大, 均匀度越高.

在以前的研究中, 我们将研究区中二叠世晚期 腕足动物由早至晚划分为二个化石群落 ${ }^{[4]}$, 即 Cryptospirifer-Tyloplecta 泥灰质软泥基底群落(第 1 6 层)和 Urushtenoidea-Uncisteges 灰质软泥基底群落 (第 7 11 层). 剖面中每一层出现的腕足类视为群落 演替过程中的一个阶段, 即亚群落阶段. 利用上述公 式, 逐层进行计算, 结果如表 1 所示, 计算的物种及 个体数见图 1 .

\subsection{2 生态系统中腕足动物群落的生产力}

生产力和生物量的测定是研究生态系统能量学 中最基本的两个参数, 目前大多数学者使用的是 $b / Q$ (生产力和生物量之比) $=9$ 的经验公式, 即: $b=9 Q$ 是目 前广泛承认的估计线虫乃至整个小型底栖动物群落 生产力的经验公式 ${ }^{[15]}$.

然而, 生物量的测定是十分困难的. 即使对于现 代底栖动物而言, 也因其涉及到采样的困难和研究 中存在的许多变量等诸多因素的影响, 无法采用传 统的野外测量生长的方式去获取生物量. 一般获得 生物量参数的方法是采用体积估算法而获得.

作为地史时期的底栖动物群落, 要实测其生物 量是绝对不可能的. 因此, 我们引入现代生物学对底

\section{表 1 合川地区中二叠世晚期腕足类物种多样性指数} 统计

\begin{tabular}{cccccc}
\hline 地层序号 & $S$ & $d$ & $H$ & $E$ & $D$ \\
\hline 11 & 6 & 1.895 & 1.713 & 0.649 & 0.196 \\
10 & 9 & 2.600 & 2.177 & 0.727 & 0.132 \\
7 & 5 & 1.735 & 1.502 & 0.652 & 0.240 \\
6 & 2 & 0.481 & 0.563 & 0.271 & 0.625 \\
5 & 2 & 0.481 & 0.661 & 0.318 & 0.532 \\
4 & 8 & 1.820 & 2.009 & 0.457 & 0.158 \\
3 & 2 & 0.369 & 0.616 & 0.215 & 0.556 \\
1 & 2 & 0.558 & 0.624 & 0.348 & 0.556 \\
\hline
\end{tabular}




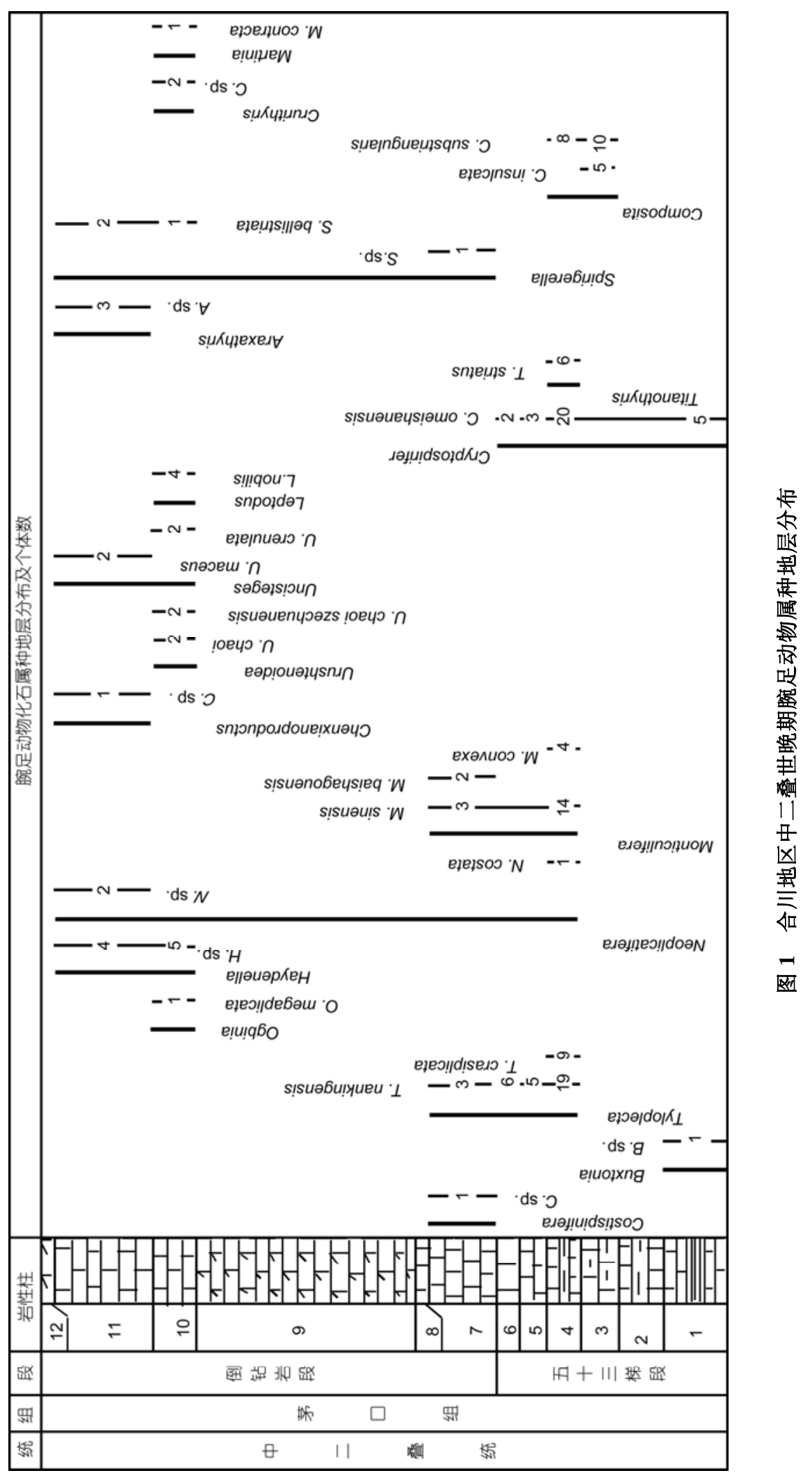


栖动物生物量参数的研究方法, 即体积估算法去求取 生物量. 由于腕足动物的贝体均由大小不等的背壳 和腹壳所构成,立体形态也不尽相同, 计算它们的体 积也只能是一种概算, 我们称其为生物量体积概算 法, 即腕足动物体积以其个体的长宽厚的乘积、并按 球体体积与其直径立方体体积的比值约为 $1 / 2$ 换算而 得出. $Q$ (生物量)概算的计算公式为

$$
Q\left(\mathrm{~mm}^{3}\right)=1 / 2 \times[L(\text { 长 }) \times W(\text { 宽 }) \times H(\text { 厚 })] .
$$

生产力采用上述小型底栖动物群落生产力的经验公 式计算, 即 $b=9 Q$.

实测剖面所在地即样方所在地. 经过对剖面中 各层腕足动物 (亚群落)的统计计算得出各亚群落生 产力值: 第 1 层(亚群落)为 $0.82 \times 10^{4} \mathrm{~cm}^{3}$, 第 3 层(亚 群落)为 $0.04 \times 10^{4} \mathrm{~cm}^{3}$, 第 4 层(亚群落)为 $5.42 \times 10^{4} \mathrm{~cm}^{3}$, 第 5 层(亚群落)为 $0.66 \times 10^{4} \mathrm{~cm}^{3}$, 第 6 层(亚群落)为 $4.79 \times 10^{4} \mathrm{~cm}^{3}$, 第 7 层(亚群落)为 $0.16 \times 10^{4} \mathrm{~cm}^{3}$, 第 10 层(亚群落)为 $0.08 \times 10^{4} \mathrm{~cm}^{3}$, 第 11 层(亚群落)为 $0.03 \times$ $10^{4} \mathrm{~cm}^{3}$.

\section{4 腕足动物群落的演替及其取代}

群落演替是指古群落在外界环境保持相对稳定 或促进下, 由古群落内部物种间相互作用而导致的 内部生物间的变化; 而由外界环境变更所引起古群 落更迭则称为群落取代. 先前的研究表明 ${ }^{[8]}$ : Cryptospirifer-Tyloplecta 泥灰质软泥基底群落在演替 过程, 是从第 1 层出现的先驱群落开始, 到第 4 层达
到顶极群落, 至第 5 和 6 层走向衰退为止, 最终在第 7 层被另一群落Urushtenoidea-Uncisteges 灰质软泥基 底群落所取代. 至此, Cryptospirifer-Tyloplecta 泥灰 质软泥基底群落的演替就此结束.

\section{2 物种多样性测度指数与生产力之间的关} 系

为了探讨物种丰富度指数、物种多样性指数、均 匀度指数、生态优势度与生产力之间的关系, 我们将 研究区腕足动物在群落演替过程中各亚群落(层)的 物种丰富度、物种多样性指数、均匀度指数、生态优 势度与其相应的生产力进行对比分析, 绘制了在中 二叠世晚期群落演替过程中它们之间的发展趋势图 (图 2).

\section{1 物种丰富度指数与生产力的关系}

如图 2 所示, 伴随 Cryptospirifer-Tyloplecta 群落 的整个演替过程: 从第 1 层先驱群落开始, 到第 4 层 达到顶极群落, 至第 5 层走向衰退为止, 物种丰富度 指数与生产力的关系一直呈现正相关关系, 且相关 性较好. 但从第 6 层开始, 包括 UrushtenoideaUncisteges 群落取代后的第 7 层以后, 它们的关系则 呈现反差极大的负相关关系.

从图 2 还可以看出, 当 Cryptospirifer-Tyloplecta 群落处于演替的先驱和发展阶段低生产力水平时,

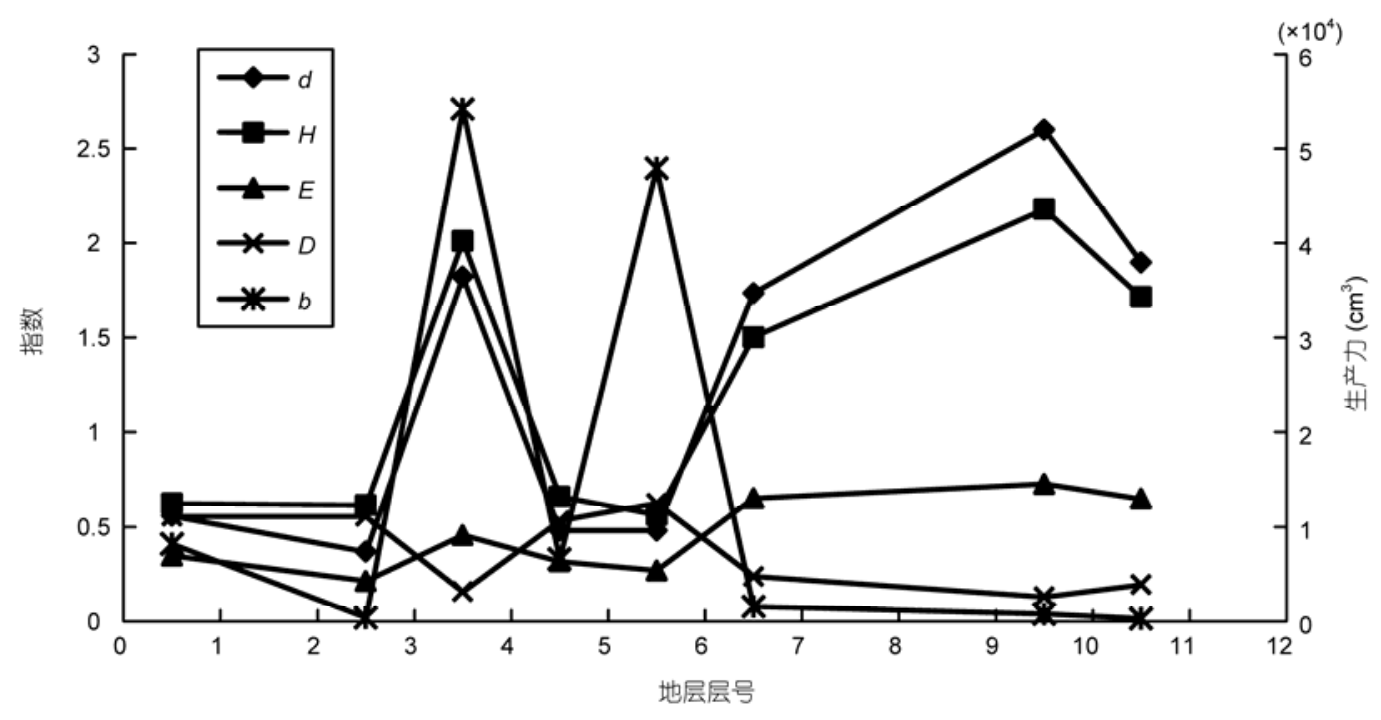

图 2 合川地区中二叠世晚期腕足动物物种丰富度、物种多样性指数、均匀度指数、生态优势度与生产力的关系图 
物种丰富度也处于较低水平; 当该群落达到顶极阶 段最高生产力 $\left(5.42 \times 10^{4} \mathrm{~cm}^{3}\right)$ 时, 物种丰富度也随之 升高, 并达到第 3 高值(1.82); 当该群落达到衰退阶 段初期低生产力时, 物种丰富度随之降低. 该规律符 合生产力与物种多样性之间的关系呈现线性关系的 观点. 但当该群落达到衰退阶段的第 6 层时, 生产力 突然升高达到第 2 高值, 而物种丰富度反而为第 2 低 值; 在群落取代整个时期, 生产力一直处于极低水 平, 而物种丰富度却表现为一系列高值, 其中, 第 10 层生产力为第 3 低值 $\left(0.08 \times 10^{4} \mathrm{~cm}^{3}\right)$, 而物种丰富度则 为第 1 高值 (2.6). 这个规律与前面的观点相矛盾, 不 符合生产力与物种多样性之间的关系呈现线性关系 的观点.

\section{2 物种多样性指数与生产力的关系}

如图 2 所示, 物种多样性指数与生产力的关系, 和物种丰富度指数相似, 也是伴随 CryptospiriferTyloplecta 群落的整个演替过程与生产力的关系呈现 正相关关系, 且相关性比物种丰富度指数更好. 但从 第 6 层开始, 包括群落取代后的第 10 层以后, 它们的 关系也呈现反差较大的负相关关系.

从图 2 还可以看出, 与物种丰富度反映的规律相 似, 当 Cryptospirifer-Tyloplecta 群落处于演替的先驱 和发展阶段低生产力水平时, 物种多样性指数也处 于较低水平; 当该群落达到顶极阶段最高生产力 $\left(5.42 \times 10^{4} \mathrm{~cm}^{3}\right)$ 时物种多样性指数也随之升高, 并达 到第 2 高值(2.009); 当该群落达到衰退阶段初期低生 产力时, 物种多样性指数随之降低. 该规律符合生产 力与物种多样性之间的关系呈现线性关系的观点. 但当该群落达到衰退阶段的第 6 层时, 生产力突然升 高达到第 2 高值 $\left(4.79 \times 10^{4} \mathrm{~cm}^{3}\right)$, 而物种多样性指数反 而为最低值 $(0.563)$; 在群落取代整个时期, 生产力一 直处于极低水平, 而物种多样性指数却表现为一系 列高值, 其中, 第 10 层生产力为第 3 低值 $\left(0.08 \times 10^{4}\right.$ $\mathrm{cm}^{3}$ ), 而物种多样性指数则为第 1 高值 (2.177). 这个 规律与前面的观点相矛盾, 不符合生产力与物种多 样性之间的关系呈现线性关系的观点.

\section{3 物种均匀度指数与生产力的关系}

如图 2 所示, 除第 6 层外, 都是伴随 Cryptospirifer-Tyloplecta 群落的整个演替过程与生产 力的关系呈现正相关关系, 但唯有群落走向衰退的
第 6 层为负相关. 然而总体来说, 相关性比物种丰富 度指数和物种多样性指数均稍差. 但从第 6 层开始, 包括群落取代后的第 7 层以后, 它们的关系则呈现反 差较小的负相关关系. 可以看出, 物种均匀度指数与 生产力的关系, 与物种丰富度和物种多样性指数所 反映的规律相似，只不过升降幅度更小.

\section{4 生态优势度与生产力的关系}

如图 2 所示, 当Cryptospirifer-Tyloplecta 群落处 于演替的先驱和发展阶段低生产力水平时, 生态优 势度也处于较低水平; 当该群落达到第 4 层顶极阶段 最高生产力 $\left(5.42 \times 10^{4} \mathrm{~cm}^{3}\right)$ 时, 生态优势度反而剧降 到第 2 低值 $(0.158)$; 当该群落达到第 5 层衰退阶段初 期低生产力 $\left(0.66 \times 10^{4} \mathrm{~cm}^{3}\right)$ 时, 生态优势度反升高到 0.532. 该规律不符合生产力与多样性之间的关系呈现 线性关系的观点. 但当该群落达到衰退阶段后期的 第 6 层时, 生产力升高达到第 2 高值 $\left(4.79 \times 10^{4} \mathrm{~cm}^{3}\right)$, 而生态优势度也随之升为最高值 $(0.625)$; 在群落取 代整个时期,生产力一直处于极低水平, 而生态优势 度也表现为一系列低值, 二者彼此相适应. 其中, 第 10 层生产力为第 3 低值 $\left(0.08 \times 10^{4} \mathrm{~cm}^{3}\right)$, 生态优势度 为最低值 $(0.132)$; 第 11 层生产力为最低值 $\left(0.04 \times 10^{4}\right.$ $\left.\mathrm{cm}^{3}\right)$, 生态优势度为第 3 低值(0.196). 可以看出, 除 第 4 和 5 层外, 其他均符合生产力与物种多样性之间 呈线性关系的观点.

\section{3 讨论}

\section{1 生产力在整个群落演替和取代过程中的变化 趋势}

本研究区在整个中二叠世晚期时期, 伴随腕足 动物群落演替和取代的全过程, 各亚群落时期生产 力变化很大. 在 Cryptospirifer-Tyloplecta 群落走向 顶极的第 4 层和 Cryptospirifer-Tyloplecta 群落走向 衰退的第 6 层各出现 1 个较大值. 其中, 第 4 层为 $5.42 \times 10^{4} \mathrm{~cm}^{3}$, 是整个中二叠世晚期的最高值. 第 6 层为 $7.66 \times 10^{4} \mathrm{~cm}^{3}$, 是该时期的第二高值. 同时, 在 整个中二叠世晚期时期还出现了 2 个低值, 最低值 出现在 Urushtenoidea-Uncisteges 取代群落后期 的第 11 层, 其生产力值为 $0.03 \times 10^{4} \mathrm{~cm}^{3}$. 而处于 Cryptospirifer-Tyloplecta 群落发展阶段的第 3 层为 
$0.04 \times 10^{4} \mathrm{~cm}^{3}$, 是第 2 低值. 可见, 生产力在整个中二 叠世晚期的变化幅度很大. 最大值是最低值(第 11 层) 的 180 余倍、是第二低值(第 3 层)的 130 余倍. 产生 这种结果的主要影响因素是因为在第 4 层和第 6 层出 现数量相对较多的 Cryptospirifer omeishanensis, 该 物种是 Cryptospirifer-Tyloplecta 群落中的特色种, 个体十分巨大，它的出现将极大地增大亚群落的生 产力值, 但从群落取代后的第 7 层开始该属灭绝.

\section{2 生态优势度与生产力出现负相关的原因}

在整个中二叠世晚期时期, 伴随腕足动物群落 演替和取代的全过程, 生态优势度指数平稳过渡, 最 大值为 0.625 , 最小值为 0.132 , 与生产力的关系除第 4 层为负相关以外, 均为正相关关系. 究其原因, 可 能与 Cryptospirifer-Tyloplecta 群落中的特色种 Cryptospirifer omeishanensis 的采集量有关. 在化石 采集的过程中, 由于该物种在本群落中特殊巨大的 形态, 发现该物种个体数量的多少将极大的影响剖 面中 1 7 层的生产力值的大小. 因而, 生态优势度指 数与生产力的关系在第 4 层出现负相关有可能是受 到化石采集不完备性的影响而造成的.

\section{3 物种丰富度、物种多样性、均匀度与生产力之 间的关系}

物种丰富度指数、物种多样性指数、均匀度指数 与生产力的关系在整个中二叠世晚期时期, 伴随腕 足动物群落演替和取代的全过程, 各亚群落时期生 产力变化出现截然相反的两个阶段. 从第 1 层开始, 到第 5 层, 物种丰富指数度、物种多样性指数、均匀 度指数与生产力呈现正相关关系. 而从第 6 层开始, 包括群落取代后的第 7 层以后, 它们的关系则呈现反
差大小不一的负相关关系. 其中, 负相关反差最大 的是物种丰富度指数, 其次为物种多样性指数, 第 三是均匀度指数. 究其原因, 可能与当时的环境条 件有关. 正负相关的转折点位于第 6 层, 正处于 Cryptospirifer-Tyloplecta 群落的衰退阶段和 Urushtenoidea-Uncisteges 群落取代的前夕, 也是环境 变化与动荡的开始时期. 我们认为, 环境的变化是影 响物种丰富指数度、物种多样性指数、均匀度指数与 生产力关系的一个十分重要的因素.

\section{4 结论}

(1) 物种多样性与生产力的关系是个十分复杂 的问题, 不可能用一种假说去表述他们之间的关系. 同时, 物种多样性是由多种指标来体现的, 不同的指 数与生产力的关系也会出现不同的规律. 所以, 一种 假说很难概括他们的规律.

（2）物种丰富度指数、物种多样性指数、均匀度 指数与生产力的关系具有一定的共性, 它们与生产 力的关系受到环境的制约.

(3) 生态优势度与生产力的关系基本上为正相 关, 基本符合前述第 3 种假说, 彼此呈线性相关关系.

(4) 当群落演替正常进行时, 物种丰富度指数、物 种多样性指数、均匀度指数与生产力的关系符合第 3 种假说, 彼此呈线性相关关系. 当外界环境干扰超过 群落承受能力时, 不仅群落出现衰退而被另一群落 取代, 而且物种丰富度指数、物种多样性指数、均匀 度指数与生产力的关系在环境的干扰下发生了逆变, 彼此出现负相关关系. 可见, 生产力与多样性之间呈 线性关系的假说应建立在群落正常演替进程中这一 前提下.

\section{参考文献}

1 殷鸿福. 从生物演化看可持续发展. 现代地质, 2000, 14: 363-365

2 Heywood V H. Global Biodiversity Assessment. Cambridge: Cambridge University Press, 1995. 201-258

3 王长庭, 龙瑞军, 丁路明, 等. 草地生态系统中物种多样性、群落稳定性和生态系统功能的关系. 草业科学, 2005, 22: 1-7

4 郑晓噮, 靳甜甜, 木丽芬, 等. 呼伦贝尔草原物种多样性与生物量、环境因子的关系. 中国草地学报, 2008, 30: 74-81

5 张全国, 张大勇. 生物多样性与生态系统功能:进展与争论. 生物多样性, 2002, 10: 49-60

6 张全国, 张大勇. 生物多样性与生态系统功能: 最新的进展与动向. 生物多样性, 2003, 11: 351-363

7 杨利民, 周广胜, 李建东. 松嫩平原草地群落物种多样性与生产力关系的研究. 植物生态学报, 2002, 26: 589-593

8 曾勇, 何锡麟, 朱美丽. 华菳山二叠纪腕足动物群与群落演替. 徐州: 中国矿业大学出版社, 1995. 4-25 
9 张庆, 牛建明, 王秀梅. 生物多样性与生态系统功能关系研究进展. 生物学通报, 2009, 44: 15-17

10 Lawton J H, Brow V K. Redundancy in ecosystems. In: Schulze E D, Money H A, eds. Biodiversity and Ecosystem Function. Ecological Studies: Analysis and Synthesis. Berlin: Springer-Verlag, 1993. 255-279

11 Tilman D, Wedin D, Knops J. Productivity and sustainability influenced by biodiversity in grassland ecosystem. Nature, 1996, 379: $718-720$

12 Naeem S, Tompson L J, Lawler S P, et al. Declining biodiversity can alter the performance of ecosystem. Nature, 1994, 368: 734-737

13 张全国, 张大勇. 生产力、可靠度与物种多样性：微宇宙实验研究. 生物多样性, 2002, 10: 135-142

14 陈梦, 刘恩斌. 生物多样性熵值测度指标的应用与分析. 南京林业大学学报, 2005, 29: 37-40

15 蔡立哲. 海洋底栖生物生态学和生物多样性研究进展. 厦门大学学报(自然科学版), 2006, 45(增刊): 83-89 